\title{
Absorptive capacity and smart companies
}

\author{
Patricia Moro González ${ }^{1,2}$, Fernando E. Garcia Muiña² \\ ${ }^{1}$ Grupo Bayes Forecast (Spain) \\ ${ }^{2}$ Universidad Rey Juan Carlos (Spain) \\ pmoro@bayesforecast.com, fernando.muina@urjc.es
}

Received March, 2014

Accepted November, 2014

\section{Abstract}

Purpose: The current competitive environment is substantially modifying the organizations' learning processes due to a global increase of available information allowing this to be transformed into knowledge. This opportunity has been exploited since the nineties by the tools of "Business Analytics" and "Business Intelligence" but, nevertheless, being integrated in the study of new organizational capacities engaged in the process of creating intelligence inside organizations is still an outstanding task. The review of the concept of absorptive capacity and a detailed study from the perspective of this new reality will be the main objective of study of this paper.

Design/methodology/approach: By comparing classical absorptive capacity and absorptive capacity from the point of view of information management tools in each one of the three stages of the organizational learning cycle, some gaps of the former are overcome/fulfilled. The academic/bibliographical references provided in this paper have been obtained from ISI web of knowledge, Scopus and Dialnet data bases, supporting the state of affairs on absorptive capacity and thereafter filtering by "Business Intelligence" and "Business Analytics". Specialized websites and Business Schools' Publications there have also been included, crowning the content on information management tools used that are currently used in the strategic consulting.

Findings: Our contribution to the literature is the development of "smart absorptive capacity". This is a new capacity emerging from the reformulation of the classical 
concept of absorptive capacity wherein some aspects of its definition that might have been omitted are emphasized. The result of this new approach is the creation of a new Theoretical Model of Organizational Intelligence, which aims to explain, within the framework of the Resources and Capabilities Theory, the competitive advantage achieved by the so-called smart companies.

Originality/value: This paper presents a novel integration of various concepts: the concept of absorptive capacity from academic research and strategic consulting associated with the tools of information management. This allows us to develop better management practices by obtaining profit from these investments and facilitating the creation of intelligence inside organizations.

Keywords: Absorptive Capacity, Business Intelligence, Business Analytics

Jel Codes: M10, M19

\section{Introduction}

There is no doubt that absorptive capacity has been one of the most repeatedly mentioned and investigated terms in organization management during the last two decades (Volberda, Foss \& Lyles, 2009), and was originally described as the ability of a company to identify, assimilate, and exploit knowledge coming from external sources (Cohen \& Levinthal, 1990). It is therefore a fascinating concept to understand how companies develop the ability to capture learning components within and outside of themselves, then retain such knowledge, and finally make use of it to improve their decisions and their organizational performance.

During the last twenty years, organizations have been experiencing important changes brought about by the surge of the digital era. The information explosion is giving rise to a more intelligent world, and more intelligent companies with new organizational, competitive, and learning strategies (Almagro Pedreño, 2012). New information is created at a frenzied rate, the means to transform it into knowledge are more and more massive, and thus the possibility to continuously create new knowledge grows exponentially.

This reality about organizational intelligence is being addressed with an excessive focus on technology with the development of new information management tools (Merino Moreno, 2007) and strategic consultancy practices involved in massive information analysis, which is paving the way for organizations to be able to capture, store, and understand vast amounts of data (Cano Giner, 2010). Managing this massive information is key for the survival of a company in the changing, dynamic, global environment 
To put in place these analytics solutions in the companies, the results must be "processable" (Kohavi, Rothleder \& Simoudis, 2002). This requires an appropriate technology and also a number of capabilities and habits in the organization (Barton \& Court, 2012; Flórez, 2012), wich will be key to really achieve an increase in organizational performance (Sharma, Reynolds, Sheepers, Seddon \& Shanks, 2010).

According to the Resources and Capabilities Theory, a more detailed determination of the resource base and the development of certain capabilities is a sustainable source of competitive advantage (Barney, 1991; Grant, 1991). Our proposal includes absorptive capacity as a strategic capability (Cohen \& Levinthal, 1990; Teece, Pisano \& Shuen, 1997) and as a variable influencing improvement in results, but we make some revisions and reformulations to the classical concept of absorptive capacity.

Our proposal presents "absorptive capacity" as a strategic, dynamic variable related to other organizational capacities.

Lane and Lubatkin (1998) found that the lack of this capability in an organization is the biggest hindrance to organizational learning and performance improvements. Developing and maintaining an absorptive capacity becomes thus critical to the company's survival and success in the long term (Lane, Koka \& Pathak, 2006).

Moreover, the increasing dynamism in the environment is forcing organizations to develop and boost their absorptive capacity (Van den Bosch, Volberda \& De Boer, 1999) along with other organizational capacities (Shinkle, 2012). Zahra and George (2002) understood absorptive capacity as a metacapacity, involving organizational routines and processes aimed at producing other related organizational capacities.

Although it is a variable theoretically formulated as a complex process, it is sometimes approach in a limited way by the researchers, who tend to restrict it to some particular tactical tasks - forgetting its strategic relevance - like innovation policies, open collaboration and innovation agreements, or internal formulation of the company's functional strategy (GonzálezSánchez \& García-Muiña, 2011).

Furthermore, too many studies have approached it as a "tangible" variable by quantifying the use of R\&D as a proxy variable (Jong \& Freel, 2010; Cohen \& Levinthal, 1994).

Maybe due to the influence of Knowledge Management studies, the absorptive capacities has been seen as a one-dimensional and static variable studying information and knowledge exchange conditions intra-extra organization (González-Sánchez \& García-Muiña, 2011; Haller, Amabile, Meissonier \& Couderc, 2011). However, organizations face significant difficulties when 
creating value out of exclusively internal knowledge sources, since information able to be transformed into knowledge is also outside and it interacts with the organization through different dimensions. We will further discuss this point throughout this document.

Since the exploitation of the concept to the full is seriously questioned (Volberda et al., 2009) and it might have been studied insufficiently without capturing the construct's nature (Zahra \& George, 2002), considering the need for an update of the concept in the light of this new competitive reality may seem justified.

Here are some questions relating the theoretical variable of absorptive capacity, the current competitive environment, and the strategic management of information within organizations. These questions will provide an answer to the limitations of the concept exposed above:

- Is the concept of absorptive capacity still valid in the current context of organizational intelligence?

- Should the foundations of the absorptive capacity be revised and adapted to this new competitive reality?

- Will the companies' absorptive capacity be modified by the use of new information management tools?

- Can we discover in the origins of the concept of absorptive capacity valuable lessons to boost competitiveness in modern organizations?

\subsection{Goals and justification}

To analyse the ideas exposed above, three fundamental objectives were defined:

- First, demarcate the concept of organizational intelligence, associating it to strategic information management, thus building a reference framework where the concept is linked to technological tools and organizational capacities.

In stead of associating the creation of intelligence with improved technological tools, more powerful and able to capture and store more data, like it is done in many papers, our approach places the stress on the relationship between intelligence and a number of organizational capacities.

The binding element that links information management tools and absorptive capacity in the organization is the "forecasting capacity", a concept used in the very definition of absorptive capacity proposed by Cohen and Levinthal in 1994, though little emphasized in the literature. 
Our research takes this forecasting capacity as a foundation and places it in the spotlight in our updated concept of absorptive capacity, and introducing the innovation of connecting it to the universe of organizational intelligence. We will call this new, updated absorptive capacity "smart absorptive capacity".

- The second goal is to revise the state of affairs regarding the concept of absorptive capacity in the current context of organizational intelligence. In this paper, we propose to overcome some deficiencies in the theoretical treatment of the concept, reformulating it and presenting innovations at each of the three stages in the absorptive capacity cycle. We will present a comparison between the classical absorptive capacity and the smart absorptive capacity at each of these stages: identification of relevant information, internal knowledge assimilation, and use of new knowledge within the organization.

- Finally, the third goal is to present, in the theoretical framework of Resources and Capabilities, a descriptive model of "organizational intelligence" based on strategic information management, along with a revised concept of absorptive capacity, as the foundations of company performance boosting.

\section{Organizational Intelligence: strategic information management and absorptive capacity}

In the current competitive world, information and data pervade the companies' value chains, transforming competition rules (Porter \& Millar, 1985). Through a wide range of applications and practices to collect, integrate, analyze, and present information, available for people at all levels (Negash, 2004; Rouach \& Santi, 2001), the organizations are acquiring a big competitive advantage, called Organizational Intelligence (Porter \& Millar, 1985).

The information industry provides tools for boosting the organizational decision-making capacity, helping shape the company's future and protecting it from the competitive threats of the markets (Porter \& Millar, 1985; Rouach \& Santi, 2001; Negash, 2004).

Table 1 contains the descriptions presented, and shows how the signs of organizational intelligence are composed of two elements: the first one is information processing and management with specific tools; the second one is the development of certain organizational capacities.

In our approach, information management tools and organizational capacities together place the creation of organizational intelligence in a strategic process for the organizations. 
The table also includes some of the organizational capacities connected to this process, such as innovative capacity, anticipation capacity, and decision-making capacities. All of them have one element in common: the forecasting capacity.

\begin{tabular}{|l|l|l|l|}
\hline Author & Sign of intelligence & \multicolumn{1}{|c|}{ Information management } & Organizational capacity \\
\hline $\begin{array}{l}\text { Porter \& } \\
\text { Millar } \\
(\mathbf{1 9 8 5 )}\end{array}$ & $\begin{array}{l}\text { Intelligence as a source } \\
\text { of competitive } \\
\text { advantage }\end{array}$ & $\begin{array}{l}\text { Embedded in the company's value } \\
\text { chain, it transforms products and } \\
\text { changes competition rules. }\end{array}$ & $\begin{array}{l}\text { Innovation: creation of } \\
\text { new business and new } \\
\text { opportunities and } \\
\text { improving value }\end{array}$ \\
\hline $\begin{array}{l}\text { Rouach \& } \\
\text { Santi } \\
(\mathbf{2 0 0 1 )}\end{array}$ & $\begin{array}{l}\text { Competitive } \\
\text { intelligence aimed at } \\
\text { overcoming threats }\end{array}$ & $\begin{array}{l}\text { Collection, processing, and } \\
\text { storage throughout the } \\
\text { organization and available for } \\
\text { everyone in it }\end{array}$ & $\begin{array}{l}\text { Anticipation: } \\
\text { Visualize the future and } \\
\text { study the competitors }\end{array}$ \\
\hline $\begin{array}{l}\text { Negash } \\
(\mathbf{2 0 0 4 )}\end{array}$ & $\begin{array}{l}\text { Business intelligence } \\
\text { aimed at supporting } \\
\text { the organization }\end{array}$ & $\begin{array}{l}\text { Information gathering, } \\
\text { integration, analysis, and } \\
\text { presentation practices. }\end{array}$ & $\begin{array}{l}\text { Decision-making: more } \\
\text { effective and efficient. }\end{array}$ \\
\hline
\end{tabular}

Tabla 1. Types of organizational intelligence

According to the Spanish dictionary of the Real Academia, to forecast is to see anticipatedly, detecting signs or evidence of what may happen in future, with the objective of providing or preparing remedies to prevent future contingencies.

Our approach, represented in Figure 1, presents organizational intelligence as an asset based on the forecasting capacity.

Stepping ahead of the competitors, making things happen before the time established or expected by the competitors is a flagrant example of how the forecasting capacity is a strategic tool in any market.

New business opportunities are achieved through organizational innovation management, which leads to anticipating and detecting changes in the environment (Morcillo Ortega, 1997).

Finally, a better capacity to make decisions and solve future problems is also determined by the capacity to foresee the environment. 


\section{Organitational Intelligence $=\mathrm{f}($ forecasting capacity $)$}

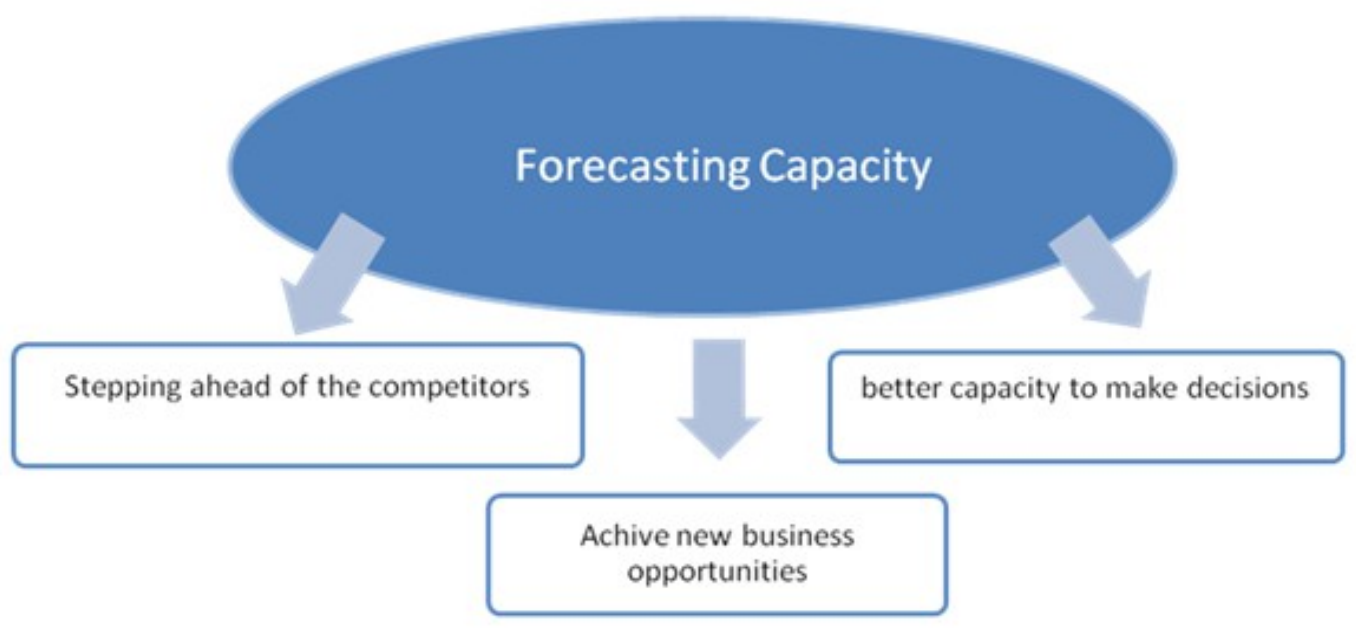

Figure 1. Organizational Intelligence and forecasting capacity

The capacity to forecast events is also at the core of human intelligence. Hawkins (2004) described how the human brain uses big amounts of stored memories to create a hierarchical model of the world as a tool to make forecasts by analogy. In the same way as the human brain does, organizations also develop their intelligence through their forecasting capacity.

Cohen and Levinthal introduced in 1994 an additional idea to the definition of absorptive capacity that had been proposed four years earlier. Their new contribution is the identification of an added value, generated through the absorptive capacity: the capacity to forecast.

Identifying, assimilating, and exploiting knowledge coming from external sources will allow organizations to more precisely forecast events in their environment (Cohen \& Levinthal, 1994). Later on, other authors, like Lane et al. (2006), continuing this idea, studied how investment in absorptive capacity allows organizations to more effectively forecast technological trends and take advantage of emerging opportunities before their competitors do so.

The forecasting capacity, which is a sign of organizational intelligence, is at the core of the absorptive capacity defined in 1994. Our reformulation of the classic concept of absorptive capacity emphasizes the underlying concept of forecasting capacity as well as its connection to strategic information management in the new competitive environment. This reformulation provides a modernized concept of absorptive capacity, more fit for the current competitive reality, which we have come to call "smart absorptive capacity". 
Our contribution to the literature is thus the transformation and redefinition of the variable "absorptive capacity" into a new concept not connected to organizational learning but to organizational intelligence.

For this purpose, we will work on the following premises:

- First premise: In the framework of this paper, the Theory of Resources and Capacities, the complex process of intelligence creation in the organizations is linked to technology developments (introducing information management tools) and to the study of different organizational capacities, including smart absorptive capacity.

- Second premise: The new information management tools, and their introduction and use within the companies, boost the intensive information processes, significantly increasing their absorptive capacity (Oh \& Teo, 2011). This in turn generates a competitive advantage.

- Third premise: The competitive advantage that the most "intelligent" companies can get is based on the forecasting capacity.

\section{Diagram Smart Companies}

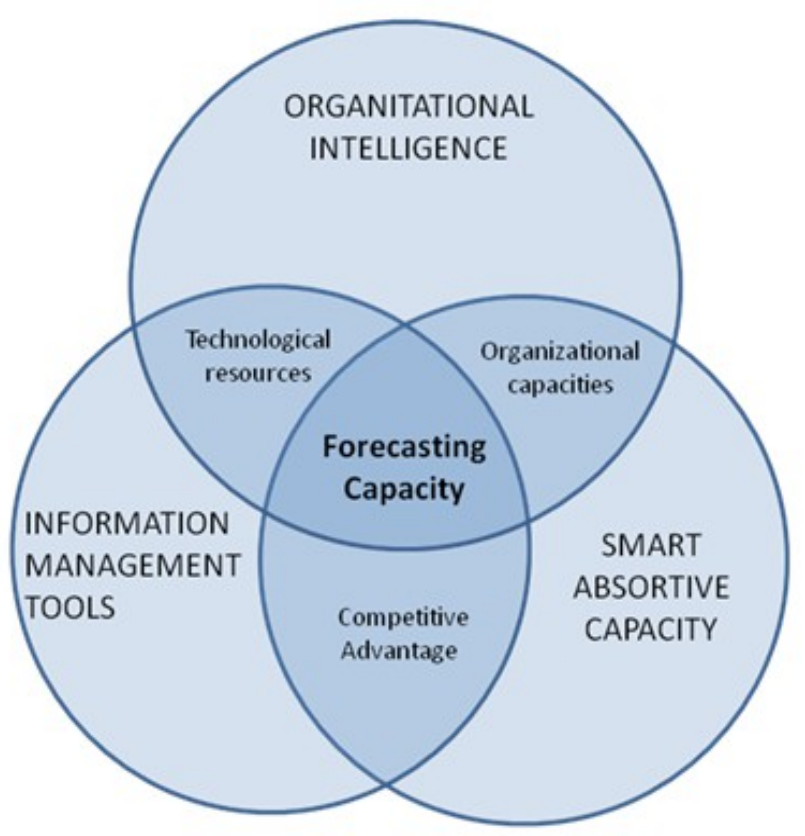

Figure 2. Intelligent organizations diagram

As the analysis made in this section has evidenced, and as is shown in Figure 2, the signs of organizational intelligence connect this competitive advantage with the ability to forecast, and the ability to forecast is provided by the smart absorptive capacity. 


\section{Information management tools}

A recent study by McAfee and Brynjolfsson of the Massachusetts Institute of Technology (2012) reveals that those companies making use of information management tools in their business operations manage to boost their productivity by $5 \%$ and their profit by $6 \%$.

Information management tools transform data into information and are able to discover new knowledge in that information. They support the process of exploring and analyzing information in order to discover trends or patterns from which new ideas can be derived and valuable conclusions can be drawn (Cano Giner, 2010).

These tools are aimed at sustainably and continuously support organizations in boosting their competitiveness, based primarily on effectively making business decisions on the basis of new knowledge extracted from relevant information about past events.

The first author to coin the expression Business Intelligence was Howard Dresner, who, as a consultant at Gartner in 1989, popularized it as an umbrella term for a collection of concepts and methods improving the decision-making process by using information from inside and outside the organization (Cano Giner, 1990).

The Business Intelligence perspective was developed in the nineties, while the first decade of the present century has witnessed the surge of Business Analytics tools, which complete the 25-year-old perspective with some technical enhancements (Davenport, 2010).

The improvement brought about by Business Analytics tools is to introduce the temporal and dynamic dimensions and the capabilities to explain and, therefore, understand the environment.

- Business Intelligence tools provide an analysis of information about past events generating reactive action in the companies (Flórez, 2012). Business Analytics tools provide forecast or simulation scenarios, which guarantee proactivity by providing awareness in advance of the potential consequences of our business decisions on the basis of assigning calculated probabilities. They also support real time decision-making, allowing, for example, to observe trends, study changes, analyze variabilities, etc. in a nimble way, constantly transforming obsolete knowledge (Flórez, 2012).

- The ability to understand is attained by applying explanatory mathematical models of each variable involved. These models serve to discover what business variables are affecting one particular process. They allow to understand each variable's behaviour, assess their business impact, and then study what risk factors can potentially have an influence in the probability that a certain scenario materializes (Flórez, 2012). 
Therefore, the improvement in the ability to understand the business matter leads to better and more effective decision-making.

- Finally, Business Analytics tools include data viewers that summarize, organize and extract key business information. The human information management potential is completely overwhelmed by technology. Modern databases, calculation engines, and other data collection tools can analyze and interpret information massively, dynamically, and associatively (Almagro Pedreño, 2012). The so-called business "dashboards" facilitate understanding of key business processes, by showing summarized key data for decision-making (Flórez, 2012).

The table below shows the main differences between Business Intelligence and Business Analytics, although both share one single fundamental objective.

\begin{tabular}{|c|c|c|}
\hline & Business Intelligence (BI) & Business Analytics (BA) \\
\hline Objectives & \multicolumn{2}{|c|}{$\begin{array}{l}\text { Sustainably and constantly support organizations to boost their competitiveness } \\
\text { by providing the information necessary to make decisions and boost organizational } \\
\text { performance. }\end{array}$} \\
\hline Methodology & $\begin{array}{l}\text { Historic data analysis. Making decisions } \\
\text { at present time. }\end{array}$ & $\begin{array}{l}\text { Explanatory, predictive mathematical } \\
\text { models. Future probability. }\end{array}$ \\
\hline $\begin{array}{l}\text { Answers these } \\
\text { questions }\end{array}$ & $\begin{array}{l}\text { What happened? When did it happen? } \\
\text { Who? How many/much? How often? } \\
\text { Where is the problem? What steps } \\
\text { should be taken? }\end{array}$ & $\begin{array}{l}\text { Why did it happen? Will it happen again } \\
\text { according to this trend ...? What happens } \\
\text { if we change ...? What is the probability } \\
\text { that it will be so? What is the most } \\
\text { probable scenario? }\end{array}$ \\
\hline
\end{tabular}

Table 2. Business Intelligence vs. Business Analytics

\section{Absorptive capacity vs. "smart" absorptive capacity}

The fundamental contribution of this paper is the study of how Business Intelligence and Business Analytics new information management tools facilitate the development of an absorptive capacity smarter that the classical absorptive capacity.

This study will be presented as a comparison between the classical absorptive capacity and the new definition proposed here, at each stage of the organizational learning process: identification of relevant information, internal assimilation of knowledge, and finally, exploitation of such knowledge within the organization. This paper aims to overcome some deficiencies in the classical concept of absorptive capacity, identified in the light of organizational intelligence. 


\section{Absorptive Capacity vs. Smart Absorptive Capacity}

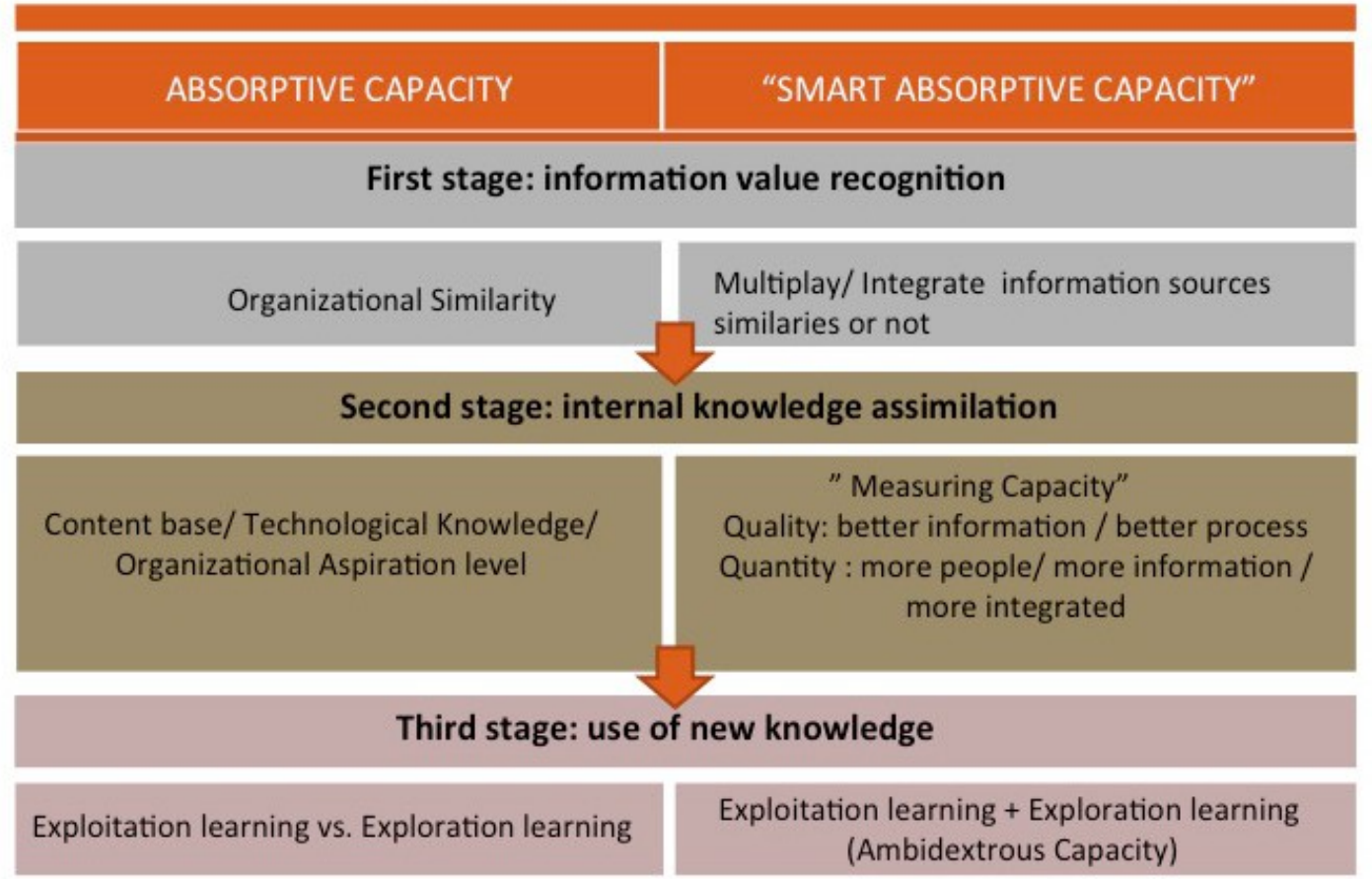

Figure 3. Absorptive capacity vs. smart absorptive capacity

\subsection{First stage: information value recognition}

The first stage rests on the organization's internal capacity to recognize the value of new information, generated outside of the company. In the case of knowledge transfer among companies, one company will learn more from another one if there is an "organizational similarity" between them, according to Lane and Lubatkin (1998). These authors define such similarity as a correspondence among different organizations at these three levels: knowledge bases, organizational structures, prevalent procedures and familiarity in the organizational problems. This concept has been also called "cognitive proximity". Cognitive proximity has a bigger impact than physical proximity in the case of companies with a high absorptive capacity (Jong \& Freel, 2010).

A company with smart absorptive capacity can increase its forecast-based absorptive capacity, and therefore its intelligence, if it has the ability to multiply and integrate the information sources embodied by the organizations and environments with which it inevitably has a higher or lesser degree of "similarity" according to Haller et al. (2011).

These authors explain that intelligence is the ability to adapt, and hence the capacity to absorb knowledge is not explained exclusively by cognitive, cultural, or organizational characteristics of similar companies, but based on the company's ability to combine different information 
sources and improve the interpretation that can be drawn from them. In the current competitive environment, this needs to be done in a massive and interrelated way.

In conclusion, in this era of big data volumes, sensors generating information relentlessly, permanently updated social media content, data-processing clouds, or engines capturing endless information, the belief that there needs to be a "similarity" between the company's knowledge and that of its external sources seems a little bit short-sighted to us.

With respect to information retrieval, for instance, new technologies, databases, search engines and, most importantly, information management tools have fostered the availability and ease of access to information of any kind, if it can be monitored. The practice of analyzing varied data, structured and unstructured, coming from internal and external sources, has been significantly developed in recent years (Oh \& Teo, 2011). These assets will be exploited to the full when the perception of absorptive capacity changes, when its limiting view is overcome and it is transformed into a more flexible, dynamic, open to the outside, and in short, a smarter absorptive capacity.

Our proposal with the smart absorptive capacity model is that, as soon as new information is available, whether it is similar or not, such information grants the opportunity to provide answers to the organization's fundamental questions and to generate a deep knowledge of what is going on in the organization's competitive environment.

\subsection{Second stage: internal knowledge assimilation}

At this stage, the analysis focuses on the way the organizations "take in" knowledge coming from outside. In other words, it describes how they transform valuable information into knowledge.

When we take a look at the bibliography regarding this point, we identify some fundamental premises that support knowledge assimilation. These premises are essentially focused on the base, type, and structure of the organization's contents originally, along with the level of organizational aspiration to take in this content.

- With respect to the organization's content base, it is determined that the company receiving knowledge usually needs substantial knowledge to reconstruct the information and transform it into useful knowledge (Cohen \& Levinthal, 1989). This previous knowledge base sits fundamentally in the organization's employees. Negri (2006) and Cohen and Levinthal (1990) detected that academic education, capacities, and a 
number of abilities related to work are decisive to attain a higher level of organizational learning.

- The analysis of the kind of previous knowledge that is necessary for this second stage of knowledge assimilation leads us to the conclusion that exclusively technological knowledge is not enough to boost the learning processes. Effective and successful organizations forge strong bonds between information technology and business knowledge (Davenport, 2013).

- If knowledge assimilation occurs inside the organization, it will change its previous knowledge structure. Zahra and George (2002) identified that this assimilation process usually entail some deficiencies: companies may successfully assimilate external knowledge but the afterwards can have trouble exploiting assimilated knowledge if it is not appropriately integrated in the organization's content structure.

- Finally, the "organizational aspiration level" capacity, defined by Cohen and Levinthal (1990) as the effort that an organization put into innovation, will boost the company's internal knowledge assimilation. According to Kim (2001), the term also refers to the amount of energy deployed by the members of an organization in order to deal with problems. Therefore, the interaction between the employees' capacity and their motivation will raise the company's knowledge assimilation level and thus also its absorptive capacity (Minbaeva, Pedersen, Bjorkman, Fey \& Park, 2003).

The development of the smart absorptive capacity in this second stage of knowledge assimilation seems to stick to the premises studied for the classic absorptive capacity.

The whole organization can develop abilities related to knowledge assimilation - spreading its knowledge base and further developing intelligence and stimulating their organizational ambition - through simple tools that are understandable for everyone involved (Barton \& Court, 2012).

To attain a bigger and better knowledge assimilation we propose, in the framework of smart absorptive capacity, understood as a metacapacity, to bind it together with the measuring capacity, which would complement this process.

Intelligence in the organizations and the business of information management involve measuring and quantifying data of different kinds: business, markets, non-controllable external variables, customers or partners, competitors, and even measuring public data, all in order to make the best business decisions (Barton \& Court, 2012). Information management tools include massive measuring of varied kinds of data and generate an assortment of indicators supporting organizational management (Merino Moreno, 2007) and transformation 
of the data into knowledge (Kohavi et al., 2002). The organizations can now efficiently engage in exchanging and assimilating knowledge through information management tools (Oh \& Teo, 2011).

Those companies including organizational intelligence tools in their strategy will be acquiring a measuring capacity and therefore a quantitative and qualitative increment in knowledge assimilation.

As the following sections will explain, the increase in the amount of knowledge assimilation will be supported by the democratization of data access, the action based ont integrated information, and the boost of data visualization.

The incremented quality of knowledge assimilated will be essentially brought about by the more accurate information diagnosis and uncertainty management that these systems provide.

\subsubsection{Quantity of assimilated knowledge}

Information management tools used to be decision-support systems only available for senior executives. The advent of the Internet and the burgeoning of Web 2.0 application made business intelligence available to lower-level employees. While senior executives and analysts have access to specialized Business Intelligence and Business Analytics tools, the rest of the employees can also be the users of similar tools differing, though, in their characteristics. (Oh \& Teo, 2011). Improving information accessibility is paramount (Barclay \& Murray, 1999).

These intelligent systems have brought about as well the opportunity to analyze integrated, and not compartmentalized, information (Barclay \& Murray, 1999) and therefore a higher probability to assimilate new knowledge, generating a contagious effect, spreading the knowledge throughout the organization (Flórez, 2012).

Our final point regarding the increment in quantity of assimilated knowledge is about the tools for business data summary view, which are part of the information management tools. These visual tools allow to understand business conditions at a glance, placing the focus on the key performance indicators (Barton \& Court, 2012). Moreover, they provide up-to-date reports to facilitate continuous internal knowledge assimilation (Kohavi et al., 2002).

In short, we can say that assimilated knowledge can be increased in quantity by making bigger amounts of integrated information reach more people. 


\subsubsection{Quality of assimilated knowledge}

Introducing the measuring capacity in the organization will increase the quality of assimilated knowledge through the purge of flaws in the data to be assimilated and an enhanced assimilation process.

The strong diagnosis and recalculation processes facilitated by information management tools minimizes the amount of errors in the organization's previous information base, i.e., it brings such information closer to reality. This process yields reliable knowledge that is the base for a more effective decision-making by the organization.

Business Intelligence and Business Analytics tools, as intelligent systems, improve the process by operating without bias and therefore outperforming human operation. These systems are much more reliable in interpreting and assimilating information, since they are able to operate without cognitive dissonance on new information or recently updated information (Predizo Team).

In addition, the forecasting models provided by Business Analytics tools produce probability scenarios where business risk can be calculated in advance (Barton \& Court, 2012). Thus, they become a very valuable tool for knowledge assimilation by the organization's senior managers in times of economic and financial uncertainty like the one we are experiencing now.

In short, our proposal for the knowledge assimilation stage is that the companies can achieve a higher quality and quantity of assimilated knowledge through the alliance of smart absorptive capacity and measuring capacity.

\subsection{Third stage: use of new knowledge}

Our study at this last stage focuses on how the organization incorporates knowledge transformed into particular operations (Zahra \& George, 2002), applies it commercially (Lane \& Lubatkin, 1998), or, in the framework of organizational intelligence, exploits this knowledge achieving a more efficient decision-making.

This last stage in the absorptive capacity process will result in a decision triggering an action: buying, selling, raise prices, implementing a marketing action, etc. (Payeras, 2013). It will be aimed at enhancing organizational performance and supporting corporate success and preservation of competitive advantage (Lane \& Lubatkin, 1998). 
Since the Decision Theory was presented in 1960 by Howard Raiffa and Robert Schlaifer at the Harard Business School, much writing has been produced around the decision-making analysis in organizations and how it helps to efficiently deal with complex problems.

Taking one decision implies considering different options when there are conflicting objectives, and subsequently deal with uncertainty about future consequences. Such uncertainty is managed with a cost-benefit function measuring the advantages of each possible consequence and the probability that they really come to happen (Goodwin \& Wright, 2004).

Providing flawless information at the right time and to the right person is the pledge made by the business of Business Intelligence and Business Analytics tools. They will maximize effectiveness in decision-making by revealing the most profitable cost-benefit function (Pratt, Raiffa \& Schlaifer, 1995).

This pledge is, to some extent, at the core of the technical progress in information management resources. According to a worldwide poll conducted by EMC Corporation in 2013, $79 \%$ of respondents believe that the tools of this kind, and essentially Business Analytics tools, boost the decision-making process.

These advantages need to be completed by business intelligence and organizational capacities developed to a much further extent than they are in most Business Intelligence or Business Analytics projects.

Our contribution is the identification and analysis of how the smart absorptive capacity results in the implementation of efficient decision-making in the organizations, complementing information management tools.

\subsubsection{Adequate information and right time}

In order to successfully carry out the process of using new knowledge, it is necessary to apply the right knowledge acquired at the preceding stage --the assimilation stage (Kallio, 2012). The organization does this through exploitation learning as defined by Lane et al. (2006), materializing the concept of absorptive capacity described by Zahra and George (2002).

However, we must take some considerations into account:

- The company's decisions should never be based exclusively on recently assimilated information, and no external knowledge captured and assimilated should be subject to direct operational or commercial exploitation (Weerawardena, O'Cass \& Julian, 2006). Therefore, is recently assimilated information the most adequate information? 
- Time and again, the companies need to use their knowledge and apply it to make decisions on the base of really uncertain grounds (Predizo Team), which sometimes leads to postpone decisions while awaiting the confirmation of some fact. What is the right time for the organization to make decisions?

To evaluate the uncertainty of a future event when making decisions, the organization needs to know if it has adequate information to make a decision or, on the contrary, it must search for new information, postponing the decision (Predizo Team). This search for new, more adequate information is the starting point of the exploration learning strategy.

Research about organizational learning has proved that companies need to balance exploitation learning and exploration learning in order to correctly use assimilated knowledge. Likewise, the organization needs to use exploitation and exploration knowledge when making decisions.

The smart absorptive capacity approach aligns with the ambidextrous organizations approach (Thusman \& O' Reilly, 2004; Oh \& Teo, 2011; López-Zapata, García-Muiña \& García Moreno, 2012; Ben-Oz \& Greve, 2012), justifying it fundamentally by the organizational environment of intelligence in the organizations.

In complex, dynamic, intensely competitive and highly uncertain environments, it becomes critical to develop the ambidextrous capacity.

- If we analyze the meaning of "adequate information", we observe that the market's dynamic forces force organizations to keep up to date regarding the evolution of their environment (López-Zapata et al., 2012), in order to make the right decisions. Global environments are rapidly changing and, therefore, exploration learning must be relentlessly practiced. The environment's dynamism increases the risk of specific knowledge about the environment going obsolete (Ben-Oz \& Greve, 2012), affecting the learning processes (Shinkle, 2012).

- About the meaning of "right time": if the organization delays a decision, its competitors may get in first (Pratt et al., 1995), which increases the risk of losing effectiveness in its decisions (Predizo Team).

Organizations are more intelligent if they have the ability to simultaneously explore end exploit acquired knowledge, applying it to their decision-making, which will be more effective and efficient. Their performance will exceed that of the companies focusing their decision-making on one of both activities at the expense of the other. 
In the competitive environment of organizational intelligence, the ambidextrous capacity supports organizations in deploying strategic manoeuvres and making decisions based on adequate information and at the right time.

\subsubsection{Right person}

To optimize the cost-benefit function in decision-making, it is necessary to prived adequate information at the right time and to the right person. This is how the knowledge assimilated in the previous stage is best used, facilitating the exploitation of knowledge and a more efficient decision-making.

Typically, organizations distribute decision-making power over its members, according to their position, from the most strategically critical decisions down to the decisions concerning microoperations (Almagro Pedreño, 2012).

Information management tools implement so-called operative decisions, which are highly massive, more easily, more immediately, with a smaller impact of errors and through a high level of automation (Predizo Team).

However, information management tools are most often sheer calculation and simulation tools, and therefore can by no means replace human decision-making in the case of strategic decisions (Almagro Pedreño, 2012). These strategic decisions involve key variables for the company like brand, strategy, customers, price, etc. They are automatic to a much lesser extent and have high-impact consequences, since they are less predictable (Pratt et al., 1995).

The smart absorptive capacity, described as one of the capacities related to strategy, supports decision-making at the highest organizational level, capturing two fundamental aspects:

- It supports a good connection between new knowledge and the adequate organizational resources, according to the level of authority bestowed by the organization on each one of them. According to Todorova and Durisin (2007), the hierarchical structure established within the organization has an impact on the ideas that are instilled in it. The authors further assert that the hierarchical structure can even inhibit the use of knowledge if it is not adapted to the knowledge assimilated.

- Todorova and Durisin (2007), in their recommendations, suggest that it is necessary to integrate individual capacities that make up the organizational absorptive capacity. For strategic decision-making, the executives' individual capacities, like their attitude toward risk, their ambition, etc. are crucial (Goodwin \& Wright, 2004). Future 
investigation should dig into the analysis of the individual capacities that are part of the smart absorptive capacity, in the stage of decision-making, i.e. in the application of knowledge. The organizational process of information analysis would be futile without the appropriate ability to analyze it (Harris, 2012).

\section{Theoretical model of organizational intelligence based on smart absorptive capacity}

As it has been proved in this paper, and after the bibliographic review outlined in Figure 4, it seems clear that putting in place Business Intelligence and Business Analytics tools by themselves can not guarantee performance in the companies. As we have described, it is along with smart absorptive capacity that this process becomes really useful and profitable for the organization.

\section{Bibliographic Review}

\section{ABSORPTIVE CAPACITY vs. SMART ABSORPTIVE CAPACITY}

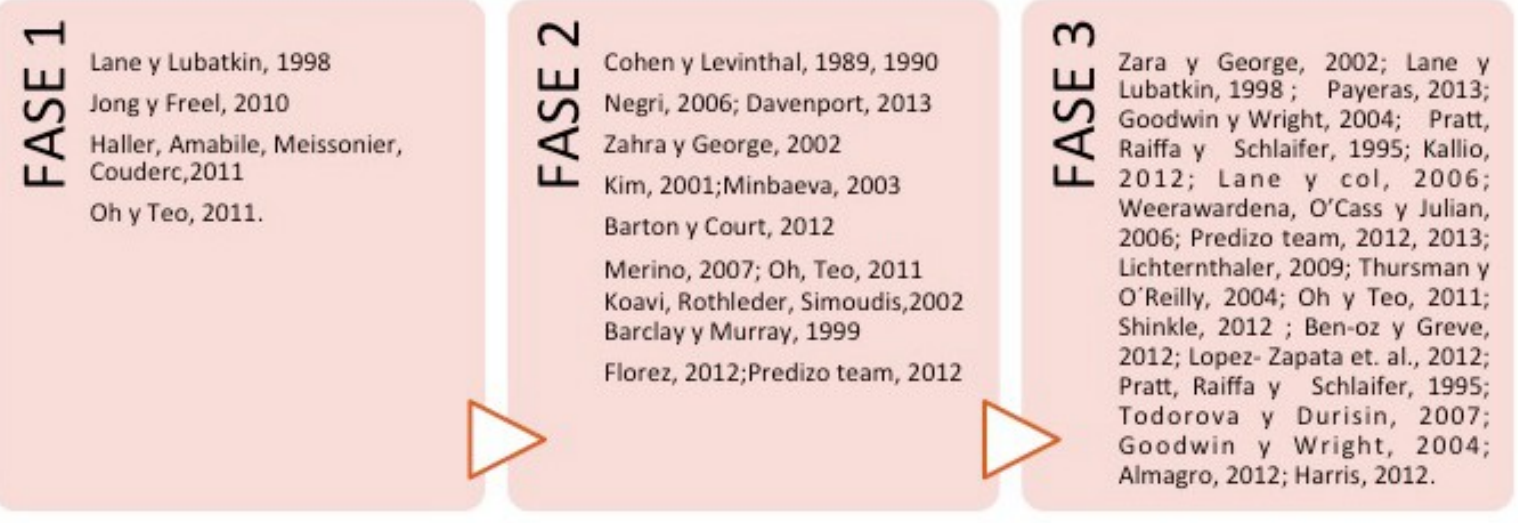

Figure 4. Bibliographic review

The theoretical model of organizational intelligence must therefore capture the way that, in the current competitive environment, certain organizational capacities - and more concretely, the smart absorptive capacity, along with information management technology - are involved in boosting organizational performance.

Zahra and George (2002) described in detail the relationship between long-term performance and its explanatory variable: absorptive capacity. They did so on the basis of environmental 
dynamism and risk of obsolescence of knowledge. This last point is directly related to our approach in the organizational intelligence environment.

Our approach also considers that in the present environment of intense competition, organizations contemplate investing in resources and developing capacities to acquire and assimilate new external knowledge (Winter, 2000).

In addition, more recent researchers state that if organizational performance is low in relation to the company's ambition level, this process of putting effort in finding and acquiring new external knowledge will be triggered, and will in turn spur an increment and movement in absorptive capacity (Ben-Oz \& Greve, 2012).

This absorptive capacity is aimed at discovering actions that will solve problems and fill some organizational gaps, ensuring better performance in the future (Ben-Oz \& Greve, 2012). Other organizational capacities studied in this paper will also be involved, like the forecasting and measuring capacities in the organization and individual capacities of decision-makers.

The conclusions of the theoretical model of organizational intelligence are displayed in Figure 5 .

\section{Theoretical Model of Organizational Intelligence}

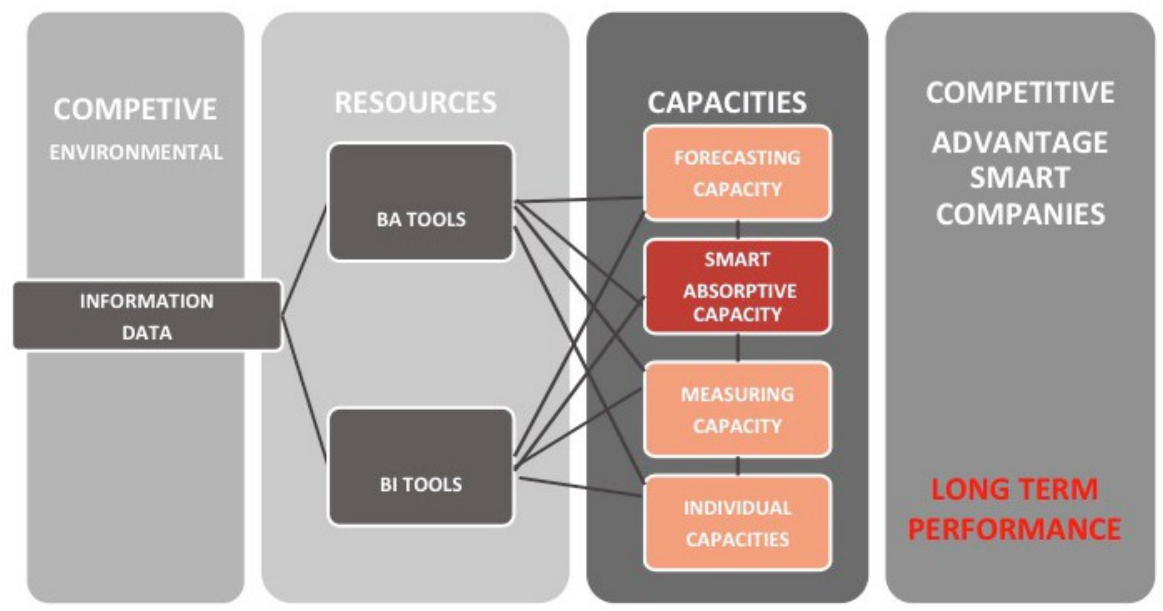

Figure 5. Organizational intelligence model

Moreover, if we add an evolutionary or dynamic perspective, we can understand the forecasting capacity as a dynamic capacity (Teece et al., 1997), generating, extending and modifying the organization's base of resources and capacities (Helfat et al., 2007). This ensures higher performance and consequently a higher probability of survival in the future. 


\section{Discussion and conclusions}

On the one hand, we know the organizational intelligence approach, which focused on putting in place Business Intelligence and Business Analytics tools that support business decisions in the competitive, dynamic, and highly uncertain environment that we live in. On the other hand, we have reviewed the organizational capacities in connection with this process - especially the "smart" absorptive capacity. Our most important conclusion is that there is a lack of connection between the "analytics" culture and the management of capacities to develop organizational knowledge (Merino Moreno, 2007).

This means that the organizations are perhaps managing information, knowledge, and intelligence in a somewhat "myopic" way (Merino Moreno, 2007), and this is having a negative impact on both the return on their investments and their strategical vision. The complex process of creating intelligence in the organizations should not be based exclusively on technology developments or information systems (high technology) but it must also include the analysis of a variety of organizational capacities.

That is precisely the recommendation that this paper proposes as the solution, on the basis of a joint analysis of both realities: information management on the one side and the development of new organizational capacities in connection with the organizational intelligence processes.

The development of these new business or organizational capacities will be highly beneficial for the business processes, which will be faster, cheaper, and more efficient (Davenport, 2013). And more concretely, the development of the smart absorptive capacity will establish for good organizational intelligence in the business processes.

The smart absorptive capacity brings understanding and efficiency to the use of information management tools within the organizations, introducing the following features:

- The process of capturing valuable information to be transformed into knowledge, making it more flexible and adaptive to the competitive environment.

- A more efficient process of assimilating knowledge, boosting quantity and quality.

- The process of putting into use the knowledge and making more efficient decisions concerning the organization's strategy.

The companies that are to succeed in the future are those leading changes in the use and development of technological tools for information management, but at the same time promoting an organizational culture of fostering and strengthening the practice of measuring and forecasting activities, and updating their traditional decision-making habits. Intelligent 
companies will not be intelligent just because they have more data, or cutting-edge information management systems, but because they are, in addition, run by leaders that ask themselves the right questions (McAfee \& Brynjolfsson, 2012).

\section{Future lines of research}

In this paper, we have chosen the model described by Cohen and Levinthal (1990) for the exploratory analysis of absorptive capacity. Their model describes three sequencial stages and initially covers the objectives or this paper. We have not chosen the model presented by Zahra and George in 2002, describing four stages --acquisition, assimilation, transformation, and exploitation. There is room for completing this paper in this direction, focusing in the two last stages of their model.

The next step for future paper would be to empirically prove the theoretical model proposed here, in companies currently developing their corporate intelligence through information management tools. The aim would be measuring how the smart absorptive capacity and the new competitive environment interact improving organizational performance, and then explain the impact of such process. Additionally, detailed analyses could be performed on different companies and sectors, with employees having different educational backgrounds and managers having different profiles, with varied hierarchical structures, or decision-making habits, among other variables.

Our work has connected organizational performance and the development of organizational and individual capacities, but there are other analogous models that can be designed, connecting other capacities involved in performance improvement brought about by business intelligence tools. Some unexplored capacities are, for instance, organizational learning, social capital, organizational memory (Sharma et al., 2010), or the measuring capacity.

Future research should delve into the relationship between smart absorptive capacity as described here and decision-making within the organization. This paper has made the initial effort of studying the impact of the smart absorptive capacity on organizational intelligence, but a deeper analysis on this point is yet to be carried out. The companies require assessment methodologies and systems to support managers in assessing their intangibles and develop a more complete management approach. This will help them make decisions with more complete information at hand and thus take smaller risks (Merino Moreno, 2007).

Finally, recent research about creation of knowledge from learning (Gil \& Carrrillo, 2013) should be taken as a base to study the variables and aspects exposed in this paper in an 
integrated way, with the aim of identifying patterns in how the companies create and develop intelligence creation environments on the basis of the learning drawn from information.

\section{References}

ALMAGRO PEDREÑO, J. (2012). Vivir en un mar de datos. Fundación Telefónica.

BARCLAY, R.O.; MURRAY, P.C. (1999). What is knowledge management?. Knowledge Praxis. Available online in: http://www.imamu.edu.sa/Scientific selections/abstracts/Abstract\%20\%20IT \%20\%203/What\%20Is\&20Knowledge\%20Management.pdf. (Accessed: September 23rd, 2010).

BARNEY, J.B. (1991). Firm Resources and sustained competitive advantage. Journal of Management, 17: 99-120. http://dx.doi.org/10.1177/014920639101700108

BARTON, D.; COURT, D. (2012). Making Advanced Analytics Work for you. Harvard Business Review on-line. (Accessed: October, 2012).

BEN-OZ, CH.; GREVE, H.R. (2012). Short- and Long-Term Performance Feedback and Absorptive Capacity. Journal of Management on-line (Accessed: November, 2012).

CANO GINER, J.L. (2010). Business Intelligence: competir con información. Madrid: Publicaciones ESADE.

COHEN, W.; LEVINTHAL, D. (1989). Innovation and Learning: The Two Faces of R \& D. The Economic Journal, 99: 569-596. http://dx.doi.org/10.2307/2233763

COHEN, W.; LEVINTHAL, D. (1990). Absorptive capacity: A new perspective on learning and innovation. Administrative Science Quarterly, 35: 128-152. http://dx.doi.org/10.2307/2393553

COHEN, W.; LEVINTHAL, D. (1994). Fortune favors the prepared firm. Management Science, 40: 227-251. http://dx.doi.org/10.1287/mnsc.40.2.227

DAVENPORT, T.H. (2010). The new World of Business Analytics. International Institute for Analytics on-line. (Accessed: March, 2010).

DAVENPORT, T.H. (2013). Big data in big companies. International Institute for Analytics online. (Accessed: June, 2013).

FLÓREZ, J.L. (2012). Ciencia y Arte en la toma de decisiones. Harvard Deusto Business Review, 9: 50-53.

GIL, A.; CARRILLO, F.J. (2013). La creación de conocimiento en las organizaciones a partir del aprendizaje. Intangible Capital, 9(3): 730-753. 
GONZÁLEZ SÁNCHEZ, R.; GARCÍA MUIÑA, F.E. (2011). Conceptualización y medición del constructo capacidad de absorción: Hacia un marco de integración. Revista de Dirección y Administración de Empresas, 18: 43-65.

GOODWIN, P.; WRIGHT, G. (2004). Decision Analysis for Management Judgement. Southern Gate, Chichester: The Atrium, John Wiley \& Sons Ltd.

GRANT, R.M. (1991). The resource-based theory of competitive advantage: Implications for strategy formulation. California Management Rev., Spring: 114-135.

http://dx.doi.org/10.2307/41166664

HALLER, C.; AMABILE, S.; MEISSONIER, R.; COUDERC, M. (2011). Business Intelligence and Absorptive Capacity of information by wineries in the Provence wine industry. International Conference, Bordeaux Management School.

HARRIS, J. (2012). Data is Useless Without the skills to analyze it. Harvard Business Review. (Accessed: September, 2012).

HAWKINS, J.; BLAKESLEE, S. (2004). On intelligence. USA: Times Book, Henry Holt and Company.

HELFAT, C.E.; FINKELSTEIN, S.; MITCHELL, W.; PETERAF, M.A.; SiNGH, H.; TEECE, D.J ET AL. (2007). Dynamic Capabilities: Understanding strategic change in organizations. Oxford: Blackwel.

JONG, J.; FREEL, M. (2010). Absorptive Capacity and the reach of collaboration in high technology small firms. Research Policy, 39: 47-54. http://dx.doi.org/10.1016/j.respol.2009.10.003

KALLIO, A. (2012). Enhancing absorptive capacity in a non-research and development context. Unpublished Doctoral Tesis.

KIM, L. (2001). Absorptive Capacity, Co-operation, and Knowledge Creation. Knowledge Emergence Social, Technical, and Evolutionary Dimensions of Knowledge Creation. Oxford University Press, Oxford: 270-286.

KOHAVI, R.; ROTHLEDER, N.J.; SIMOUDIS, E. (2002). Emerging trends in Business Analytics. Journals \& Magazines - Association for Computing Machinery - ACM, 45(8): 45-48.

LANE, P.; KOKA, B.; PATHAK, S. (2006). The reification of absorptive capacity: a critical review and rejuvenation of the construct. Academy of Management Review, 31(4): 833-863. http://dx.doi.org/10.5465/AMR.2006.22527456

LANE, P.; LUBATKIN, M. (1998). Relative absorptive capacity and Interorganizational learning. Strategic Management Journal, 19 (5): 461-477. 
LÓPEZ ZAPATA, E.; GARCÍA MUIÑA, F.E; GARCIA MORENO, S. (2012). De la organización que aprende a la organización ambidiestra: Evolución teórica del aprendizaje organizativo. Cuadernos de Administración, 25(45): 11-37.

McAFEE, A.; BRYNJOLFSSON, E. (2012). Big data: The Management Revolution. Harward Business Review on-line. (Accessed: October, 2012).

MÉNDEZ, L. Business Analytics como estrategia competitiva en tiempos de crisis. http://www.sas.com/offices/europe/spain/prodsol/spotlights/ba crisis.html.

MERINO MORENO, C. (2007). Inteligencia organizativa y capital intelectual: un ejercicio de integración. Innovar, 17(29): 07-26.

MinbaeVA, D.; PEDERSEN, T.; BJORKMAN, I.; FEY, CF.; PARK, H.J. (2003). MNC Knowledge transfer, subsidiary absorptive capacity, and HRM. Journal of International Business Studies, 34: 586-599. http://dx.doi.org/10.1057/palgrave.jibs. 8400056

MORCILLO ORTEGA, P. (1997). Dirección estratégica de la tecnología e innovación: un enfoque de competencias. Madrid: Civitas.

NEGASH, S. (2004). Business Intelligence. Communications of the Association for Information Systems, 13: 177-195.

NEGRI, F. DE (2006). Determinantes da capacidade de absorção das firmas brasileira: qual a influencia do perfil da moa de obra?. In NEGRI, J.A. DE; NEGRI, F. DE; COELHO, D. Tecnologia, exportaçao e emprego. Brasilia: IPEA, 4: 101-122.

OH, L.B.; TEO, H.H. (2011). The impact of business intelligence technologies on organizational absorptive capacity and ambidextrous innovation competence. Available online in: http//www.decisionsciences.org/

PAYERAS, M. (2013). Está su empresa lista para una iniciativa de big-data?. Available online in: www.empresas.it.

PORTER, M.; MILLAR, V. (1985). How information gives you competitive advantage. Harvard Business Review, 63(4): 149-160.

PRATT, J.W.; RAIFFA, H.; SCHLAIFER, R. (1995). Introduction to Statistical Decision Theory (5th ed.). Cambridge, MA: The MIT Press.

PREDIZO TEAM. http://www.predizo.com. 3 worst habits that keep your company from becoming data driven.

ROUACH, D.; SANTI, P. (2001). Competitive Intelligence Adds Value: Five Intelligence Attitudes. European Management Journal, 19(5): 552-559. http://dx.doi.org/10.1016/S02632373(01)00069-X 
SHARMA, R.; REYNOLDS, P.; SHEEPERS, R.; SEDDON, P.B; SHANKS, G. (2010). Business analytics and competitive advantage: a review and a research agenda. IOS Press, 5: 187-198.

SHINKLE, G.A. (2012). Organizational aspirations, reference points, and goals: Building on the past and aiming for the future. Journal of Management, 38: 415-455.

http://dx.doi.org/10.1177/0149206311419856

TEECE, D.; PISANO, G.; SHUEN, A. (1997). Dynamic Capabilities and Strategic Management. Strategic Management Journal, 18(7): 509-533.

http://dx.doi.org/10.1002/(SICI)1097-0266(199708)18:7<509::AID-SMJ882>3.0.CO;2-Z

TODOROVA, G.; DURISIN, B. (2007). Absorptive capacity: Valuing are conceptualization. Academy of Management Review, 32(3): 774-786. http://dx.doi.org/10.5465/AMR.2007.25275513

TUSHMAN, M.; O'REILLY, CH.A. (2004). Ambidextrous Organization. Harvard Business Review on-line. (Accessed: April, 2004).

VAN DEN BOSCH, F.; VOLBERDA, H.; DE BOER, M. (1999). Coevolution of Firm Absorptive Capacity and Knowledge Environment: Organizational Forms and Combinative Capabilities. Organization Science, 10(5): 551-568. http://dx.doi.org/10.1287/orsc.10.5.551

VOLBERDA, H.W.; FOSS, N.J.; LYLES, M.A. (2009). Absorbing the concept of absorptive capacity: How to realize its potential in the organization field. Organization Science, 21(4): 931-951. http://dx.doi.org/10.1287/orsc.1090.0503

WEERAWARDENA, J.; O'CASS, A.; JULIAN, C. (2006). Does industry matter? Examining the role of industry structure and organizational learning in innovation and brand performance. Journal of Business Research, 59: 37-45. http://dx.doi.org/10.1016/j.jbusres.2005.02.004

WINTER, G.S. (2000). The satisfying principle in capability learning. Strategic Management Journal, 21: 981-996.

http://dx.doi.org/10.1002/1097-0266(200010/11)21:10/11<981::AID-SMJ125>3.0.CO;2-4

ZAHRA, S.A.; GEORGE, G. (2002). Absorptive capacity: A review, reconceptualization and extension. Academy of Management review, 27: 185-203.

Intangible Capital, 2014 (www.intangiblecapital.org)

\section{(2)}

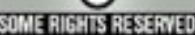

Article's contents are provided on a Attribution-Non Commercial 3.0 Creative commons license. Readers are allowed to copy, distribute and communicate article's contents, provided the author's and Intangible Capital's names are included. It must not be used for commercial purposes. To see the complete license contents, please visit http://creativecommons.org/licenses/by-nc/3.0/. 